\title{
Spikelet Proteomic Response to Combined Water Deficit and Heat Stress in Rice (Oryza sativa cv. N22)
}

\author{
S. V. Krishna Jagadish • Raveendran Muthurajan • \\ Zhongwen W. Rang • Richard Malo • Sigrid Heuer • \\ John Bennett $\cdot$ Peter Q. Craufurd
}

Received: 4 November 2010 / Accepted: 6 March 2011 / Published online: 30 March 2011

(C) Springer Science+Business Media, LLC 2011

\begin{abstract}
In future climates, rice crops will be frequently exposed to water deficit and heat stress at the most sensitive flowering stage, causing spikelet sterility and yield losses. Water deficit alone and in combination with heat stress significantly reduced peduncle elongation, trapping $32 \%$ and $55 \%$ of spikelets within the leaf sheath, respectively. Trapped spikelets had lower spikelet fertility $(66 \%$ in control) than those exserted normally (>93\%). Average weighted fertility of exserted spikelets was lowest with heat stress $(35 \%)$ but higher with combined stress $(44 \%)$, suggesting acquired thermo-tolerance when preceded by water-deficit stress. Proteins favoring pollen germination, i.e., pollen allergens and beta expansin, were highly upregulated with water deficit but were at normal levels under
\end{abstract}

Electronic supplementary material The online version of this article (doi:10.1007/s12284-011-9059-x) contains supplementary material, which is available to authorized users.

S. V. K. Jagadish $\cdot$ R. Muthurajan · Z. W. Rang $\cdot$ R. Malo •

$\mathrm{S}$. Heuer $\cdot$ J. Bennett

Plant Breeding, Genetics, and Biotechnology Division,

International Rice Research Institute,

Metro Manila, Philippines

S. V. K. Jagadish $・$ P. Q. Craufurd $(\bowtie)$

Plant Environment Laboratory,

University of Reading, Cutbush Lane,

Shinfield,

Reading RG2 9AF, UK

e-mail: P.Craufurd@cgiar.org

Z. W. Rang

College of Agronomy, Hunan Agricultural University,

Changsha 410128, China

Present Address:

P. Q. Craufurd

Agroecosystems, ICRISAT,

Patancheru AP 502324, India combined stress. The chaperonic heat shock transcripts and proteins were significantly up-regulated under combined stress compared with either heat or water deficit. The importance of spikelet proteins responsive to water deficit and heat stress to critical physiological processes during flowering is discussed.

Keywords Flowering · Heat - Oryza sativa Protein - Rice . Spikelet fertility . Water deficit

\section{Introduction}

Global warming could pose a serious threat to developing countries, reducing the world's agricultural gross domestic product by up to $16 \%$ by 2020 (Cline 2007). Simultaneously, the prices of agricultural commodities are predicted to increase by $40 \%$ with a $3^{\circ} \mathrm{C}$ increase in global temperature (Easterling et al. 2007). Furthermore, global climatic models predict an increase in mean surface air temperature $2.0^{\circ} \mathrm{C}$ to $4.5^{\circ} \mathrm{C}$ with an increased variability about this mean (IPCC 2007). Significant decline in precipitation in subtropical regions will double the area under rice (Oryza sativa) cultivation affected by water deficit stress (IPCC 2007; Wassmann et al. 2009). Therefore, a sustained increase in rice production in the future will have to be met from much drier and warmer environments. Recently, Wassmann et al. (2009) showed through spatial analysis that high-temperature stress during the susceptible reproductive stage may coincide with periods of water deficit in parts of Bangladesh, eastern India, southern Myanmar, and northern Thailand. Therefore, it is necessary to study and understand the effects of and interactions between water deficit and high temperature at flowering in rice. 
Water deficit (Liu et al. 2006) or heat stress (Jagadish et al. 2007, 2008, 2010) during flowering causes spikelet sterility in rice by affecting anther dehiscence, pollination, and pollen germination. Most abiotic stress studies impose only a single stress condition, whereas, under field conditions, a combination of stresses generally occur. Although the effects of combined heat and water-deficit stress have not been studied extensively on whole plants, studies have been conducted on the effect of water-deficit stress and heat shock in Arabidopsis (Arabidopsis thaliana; Rizhsky et al. 2004) and tobacco (Nicotiana tabacum; Rizhsky et al. 2002) at the transcript level. These studies suggested that the response of plants to combined stress is different from water deficit or heat stress alone, and that the effect of a subsequent stress can be reduced by a prior exposure to a different independent stress, i.e., acclimation occurs. For example, 770 transcripts were altered under combined stress that were not altered by either water deficit or heat stress, further indicating that combined stress is a new state of stress rather than just a sum of two different stresses (Mittler 2006). However, transcript-level (mRNA) expression does not always correlate to the quality and quantity of the gene product, i.e., proteins (Abbott 1999; Pandey and Mann 2000; Zivy and de Vienne 2000), because of alternative splicing and post-translational modifications (Komatsu 2005). Hence, 2D protein expression has been extensively employed in a wide range of studies to analyze different stages of pollen development (Imin et al. 2001; Kerim et al. 2003; Dai et al. 2006) and cold stress at the young microspore stage (Hayashi et al. 2006; Imin et al. 2004).

Rice cv. N22 is known to be tolerant of both water deficit (Selote and Chopra 2004) and heat stress (Yoshida et al. 1981; Prasad et al. 2006; Jagadish et al. 2008, 2010) at flowering stage. Hence, N22 was used to study the response to water deficit and heat stress interaction with the following objectives: (1) to test the hypothesis in rice that "subsequent stress effects can be reduced by a previous independent exposure to a different stress (Rizhsky et al. 2002)" at both the physiological and proteomic level; and (2) to identify proteins responsive to water deficit, heat, or combined water deficit and heat stress in rice spikelets. The importance of the identified spikelet proteins responsive to water deficit and heat stress, independently and in combination, to critical physiological processes during flowering is discussed.

\section{Results}

Peduncle length and spikelet fertility

In the control treatment, peduncles were 33 to $38 \mathrm{~cm}$ long and panicles were exserted (i.e. thrust out of leaf sheath) normally, with $\leq 5 \%$ of spikelets remaining trapped in the leaf sheath (Table 1). Fertility of spikelets outside the leaf sheath was $>92 \%$, while those in the leaf sheath were about $65 \%$ fertile. The overall weighted fertility was $92 \%$ to $95 \%$ in controls.

High temperature reduced peduncle length slightly (by about $3 \mathrm{~cm}$ or $8 \%$; Supplementary Fig. 1), but had no effect on the proportion of spikelets remaining trapped in the leaf sheath compared with the control. High temperature reduced spikelet fertility in all spikelets by $>55 \%$ in those outside the leaf sheath and by $>90 \%$ in those trapped in the leaf sheath. The weighted average fertility was $29 \%$ and $42 \%$ in experiments 2 and 3 , respectively, reflecting the longer duration of high-temperature exposure in experiment 2 (5 days) versus experiment 3 (4 days).

Water deficit significantly reduced peduncle length by about $30 \%$, from 33 to $38 \mathrm{~cm}$ to 23 to $27 \mathrm{~cm}$, and panicles were therefore not fully exserted. As a consequence, $32 \%$ of the spikelets were trapped in their leaf sheath. Fertility of trapped spikelets was similar to that in controls, about $64 \%$ to $72 \%$. However, fertility of spikelets outside the leaf sheath was reduced slightly compared with the controls, and the weighted average fertility was therefore $77 \%$ to $82 \%$ compared with $>92 \%$ in the controls (Table 1 ).

The combined water deficit and heat treatment, which reduced peduncle length only slightly more than in the water-deficit treatment (Supplementary Fig. 1), nonetheless had a larger effect on panicle exsertion and $52 \%$ to $59 \%$ of the spikelets failed to emerge from the leaf sheath. Fertility of these trapped spikelets was reduced compared with the water-deficit-alone treatment (18\% to $28 \%$ versus $64 \%$ to $72 \%$ ), but greater than for the heat-alone treatment $(0 \%$ to $6 \%)$. The fertility of spikelets exserted from the leaf sheath was also lower with the combined heat and water deficit (65\% to $74 \%)$ than in water-deficit alone $(84 \%$ to $86 \%)$, but again was greater than with heat alone $(29 \%$ to $44 \%)$. Effects on fertility were greater in experiment 2 with 5-day exposure compared with experiment 3 with 4-day exposure to high temperature. Thus, in spikelets within and outside the leaf sheath, the combined effects of heat and water deficit resulted in higher fertility than high temperature alone, and this advantage was greater where exposure to high temperature was for a longer period (Table 1).

Number of germinated pollen on the stigma

The number of germinated pollen on the stigma ranged from 8 to 28 in experiment 2 and from 9 to 49 in experiment 3 , and pollen count on the stigma was significantly affected by stress in both experiments $(P<0.001)$. High temperature alone $(P<0.001)$ or combined with water deficit $(P<0.01)$ had significantly fewer germinated pollen than in the control, 
Table 1 The total number of spikelets produced in the four treatments in experiments 2 and 3, the proportions inside and outside the leaf sheath and their respective spikelet fertility, and the weighted spikelet fertility

Treatment Total number of spikelets Spikelets trapped inside leaf sheath Spikelets exserted from leaf sheath Weighted spikelet fertility (\%)

Number (\%) Spikelet fertility (\%) Number (\%) $\quad$ Spikelet fertility (\%)

Experiment 2

$\begin{array}{lcccccc}\text { Control } & 123( \pm 8.5) & 4.9( \pm 1.9) & 66.5( \pm 1.4) & 95.1( \pm 1.9) & 96.6( \pm 0.6) & 95.1 \\ \text { Heat } & 133( \pm 12.4) & 0.5( \pm 0.5) & 0.0 & 99.5( \pm 0.5) & 28.7( \pm 8.7) & 28.6 \\ \text { Water deficit } & 132( \pm 5.3) & 32.0( \pm 8.1) & 72.0( \pm 7.5) & 68.0( \pm 8.1) & 86.4( \pm 5.6) & 81.8 \\ \text { Combined } & 138( \pm 3.6) & 59.1( \pm 10.6) & 28.0( \pm 2.5) & 40.9( \pm 10.6) & 65.0( \pm 6.1) & 43.1 \\ \text { Experiment } 3 & & & & & & \\ \text { Control } & 125( \pm 11.0) & 4.2( \pm 2.0) & 64.8( \pm 8.6) & 95.8( \pm 2.0) & 92.9( \pm 1.2) & 91.7 \\ \text { Heat } & 98( \pm 8.3) & 4.4( \pm 2.2) & 5.8( \pm 4.4) & 95.6( \pm 2.2) & 43.5( \pm 4.1) & 41.8 \\ \text { Water deficit } & 127( \pm 10.8) & 32.4( \pm 7.5) & 63.7( \pm 4.2) & 67.6( \pm 7.5) & 84.1( \pm 2.7) & 77.5 \\ \text { Combined } & 118( \pm 9.3) & 51.5( \pm 4.8) & 18.1( \pm 6.0) & 48.5( \pm 4.8) & 73.8( \pm 4.8) & 45.0\end{array}$

Values in parentheses are $\pm \mathrm{SE}$

while in the water-deficit treatment counts were similar to those in the control $(P=0.21)$.

There is usually a quantitative relationship between spikelet fertility and the number of germinated pollen grains, with the critical number of germinated pollen on the stigma for normal fertility being between 10 and 20 (Matsui et al. 2000; Jagadish et al. 2010). In our experiments, the relation between fertility and germinated pollen number was as expected in the control, water deficit, and high-temperature treatments (Fig. 1), with low pollen counts at high temperature resulting in low fertility and stigmas with $>15$ germinated pollen having high fertility.
However, in the combined heat and water-deficit treatment, stigmas with $<10$ germinated pollen grains achieved $65 \%$ to $73 \%$ spikelet fertility and clearly this treatment behaved very differently from the others.

Proteomic analysis of spikelets exposed to water deficit and heat stress

The protein expression pattern of rice spikelets obtained from experiment 1 and subjected to water deficit, heat, and combined stress was analyzed by the 2D-PAGE approach. Initially, proteins were separated on IPG strips of a wider $\mathrm{pH}$

Table 2 Annotation of water deficit, heat, and combined-stress-responsive proteins identified from spikelets of rice cultivar N22

\begin{tabular}{|c|c|c|c|c|c|c|c|}
\hline Protein (spot) & $\mathrm{pI}^{\mathrm{a}}$ & $\mathrm{Mr}^{\mathrm{a}}$ & Coverage $(\%)$ & Peptides matched & $\mathrm{pI}^{\mathrm{b}}$ & $\mathrm{Mr}^{\mathrm{b}}$ & Accession number ${ }^{\mathrm{c}}$ \\
\hline Putative group 3 pollen allergen (Spot 1$)$ & 5.55 & 06 & 67 & 79 & 5.37 & 12.0 & Os06g0655200 \\
\hline Soluble inorganic pyrophosphatase (Spot 2) & 6.11 & 36 & 91 & 187 & 5.90 & 23.0 & Os $10 \mathrm{~g} 0406100$ \\
\hline Putative group 3 pollen allergen (Spot 3$)$ & 5.18 & 10 & 41 & 48 & 5.46 & 12.3 & OSJNBa0050F15.8 \\
\hline Putative pollen allergen Ph1 p 11 (Spot 4) & 5.49 & 30 & 63 & 111 & 5.76 & 19.0 & Os06g0556600 \\
\hline Putative fructokinase (Spot 5) & 5.12 & 56 & 73 & 248 & 5.02 & 35.0 & P0498H04.29 \\
\hline 17.4-kDa class I heat shock protein [HSP] (Spot 10) & 5.74 & 20 & 57 & 93 & 5.80 & 17.9 & OJ1364E02.6 \\
\hline 16.9-kDa low-molecular-weight HSP (Spot 11) & 6.15 & 19 & 84 & 127 & 6.18 & 16.9 & P0443D08.5 \\
\hline Putative beta expansin (Spot 23) & 6.54 & 44 & 54 & 145 & 6.34 & 28.6 & OSJNBa0009C08.15 \\
\hline Unknown protein (Spot 7) & 5.26 & 16 & 44 & 57 & 5.08 & 13.7 & Os02g0800300 \\
\hline Unknown protein (Spot 19) & 5.08 & 34 & 61 & 137 & 5.45 & 23.4 & B1049E04.7-1 \\
\hline Novel protein ${ }^{\mathrm{d}}$ (Spot 25) & 5.45 & 32 & & & & & \\
\hline
\end{tabular}

Spots were excised from 2D gels where the spot was prominent irrespective of the treatment

Coverage (\%) percentage of sequence coverage obtained with identified peptides with Mascot software for the orthologous protein

${ }^{\mathrm{a}}$ Experimental $\mathrm{pI}, \mathrm{Mr}$

${ }^{\mathrm{b}}$ Theoretical $\mathrm{pI}$ and $\mathrm{Mr}$

${ }^{c}$ Accession number from NCBI (www.ncbi.nlm.nih.gov/gene/) all matching to rice

${ }^{\mathrm{d}}$ Not identified in the existing database 


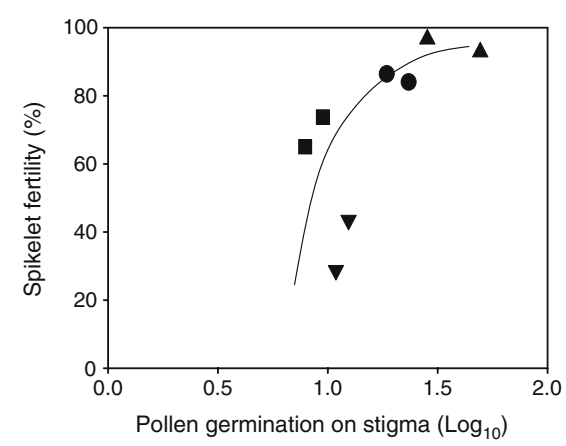

Fig. 1 Number of pollen germinated on the stigma and spikelet fertility under control $(\mathrm{C}$, triangle $)$, heat $(\mathrm{H}$, inverted triangle $)$, water deficit (WD, circle), and combined stress $(\mathrm{WD}+\mathrm{H}$, square).

range (3-10) but strips of narrower $\mathrm{pH}$ range (4-7) were used for analytical purposes as very few spots were identified in the $\mathrm{pH}$ ranges of 3-4 and 7-10. Profiling of the proteins expressed in spikelets using a 2D-PAGE strategy revealed the presence of approximately 500 clear and consistent protein spots, of which 29 spots showed a differential expression to water deficit, heat, and/or combined stress. A representative master gel used for cross comparison of protein expression between treatments and replications is shown in Fig. 2 and the variation in expression among the 29 spots is presented in Supplementary Table 1. Among the responsive proteins, the majority of them were associated exclusively with waterdeficit stress, and those proteins responsive to heat stress were responsive to water-deficit stress also. Most of the water deficit and heat-responsive proteins were up-regulated and only a few of them were down-regulated (Supplementary Table 1). Three replicate abundance ratios under control, water deficit, heat, and combined stress were determined and spots varying significantly both at $5 \%(P<0.05)$ and with approximately greater than or equal to twofold changes were considered for further analysis. Hence, 11 out of the 29 differential expressed protein spots fitting these criteria were analyzed by mass spectrometry (see supplementary Fig. 2a, $\mathrm{b}$, c, and d showing representative control, water deficit, heat, and combined stress gels indicating all the 11 sequenced protein spots). Two spots $(1,5)$ were extremely close to satisfying the above set criteria and were included in the analysis (Table 2).

Significant protein spots were analyzed by mass spectrometry and the Peptide Mass Fingerprint was used for database searching in TIGR (www.tigr.org/tdb/e2k1/osa1/index.shtml; Table 2). Out of the 11 protein sequences, similarities to annotated proteins were found coding for pollen allergens, low-molecular-weight heat shock proteins (HSPs), beta expansin, soluble inorganic pyrophosphatase, putative fructokinase, and two unknown proteins. The expression of these proteins was different during water deficit or heat stress and/ or combined stress (Figs. 3, 4 and Table 3). Interestingly, among the eight significantly up-regulated proteins under water-deficit stress, six of them exhibited a plastic response with combined stress by reverting back to expression levels similar to control conditions (Table 3). However, both heat shock proteins had a much higher expression under combined stress than with independent water deficit and heat stress. Transcript-level expression also resulted in an identical trend on the first day of stress and maintained significantly higher expression even after four consecutive days of stress exposure (Fig. 5). Two down-regulated proteins in response to
Fig. 2 A master gel from 2D electrophoresis using 4-7 $\mathrm{pH}$ IPG strips showing all 29 differentially expressed spikelet proteins (white arrowheads) under exposure to water deficit, heat, and/or combined stress. First-dimensional focusing (IEF) was done by using $17-\mathrm{cm}$ IPG strips with a $\mathrm{pH}$ 4-7 loaded with $100 \mu \mathrm{g}$ of total spikelet protein. In the second-dimension SDSPAGE, $12 \%$ gels were used. Experimental molecular weight was fixed by internal markers identified earlier with the sample and indicated by $M r$.

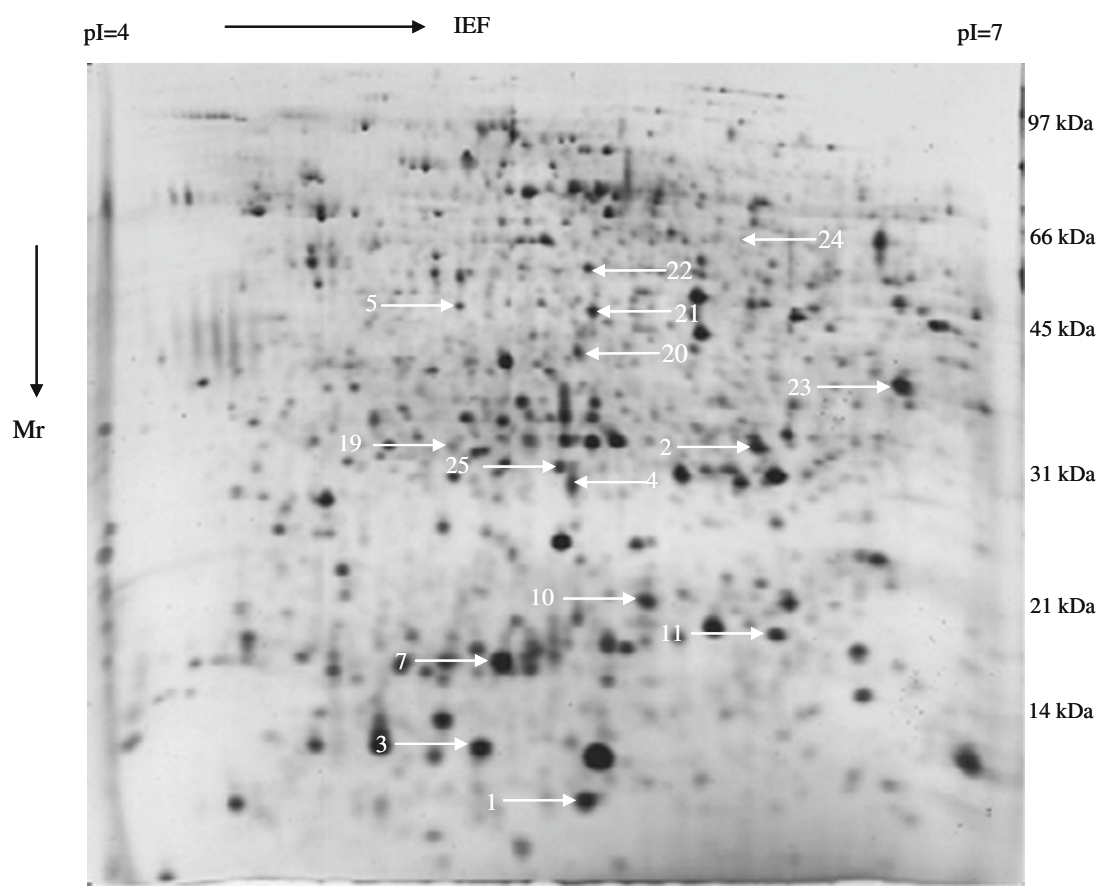


Table 3 Mean abundance ratio (Percentage of abundance of stress/Percentage of abundance of control) for the analyzed 11 protein spots responsive to heat, water deficit, or water deficit and heat stress

Significantly up-regulated proteins are highlighted in bold $n s$ non-significant

${ }^{*}$ significant at $5 \%$; ${ }^{* *}$ significant at $1 \% ;{ }^{* * *}$ significant at $0.1 \%$

\begin{tabular}{lccc}
\hline Protein (spot) & \multicolumn{2}{l}{ Mean abundance ratio } & \\
\cline { 2 - 4 } & Water deficit & Heat & Water deficit+heat \\
\hline Putative group 3 pollen allergen (Spot 1) & $1.86 \mathrm{~ns}$ & $0.69 \mathrm{~ns}$ & $1.22 \mathrm{~ns}$ \\
Soluble inorganic pyrophosphatase (Spot 2) & $\mathbf{2 . 5 4}^{* * *}$ & $1.16 \mathrm{~ns}$ & $\mathbf{1 . 8 4}^{*}$ \\
Putative group 3 pollen allergen (Spot 3) & $\mathbf{2 . 3 9}^{*}$ & $1.28 \mathrm{~ns}$ & $\mathbf{2 . 0 6}^{*}$ \\
Putative pollen allergen Ph1 p 11 (Spot 4) & $\mathbf{3 . 6 9}^{* * *}$ & $1.23 \mathrm{~ns}$ & $1.47 \mathrm{~ns}$ \\
Putative fructokinase (Spot 5) & $0.55 \mathrm{~ns}$ & $1.17 \mathrm{~ns}$ & $0.93 \mathrm{~ns}$ \\
17.4-kDa class I HSP (Spot 10) & $\mathbf{4 . 1 3}^{*}$ & $\mathbf{4 . 7 8}^{* *}$ & $\mathbf{6 . 5 3}^{* * *}$ \\
16.9-kDa low-molecular-weight HSP (Spot 11) & $\mathbf{2 2 . 6 5}^{* *}$ & $\mathbf{2 3 . 8 7 ^ { * * }}$ & $\mathbf{3 6 . 1 6}$ \\
Putative beta expansin (Spot 23) & $\mathbf{8 . 0 0}^{* * *}$ & $0.99 \mathrm{~ns}$ & $2.23 \mathrm{~ns}$ \\
Unknown protein (Spot 7) & $\mathbf{2 . 0 4}^{* *}$ & $0.83 \mathrm{~ns}$ & $1.14 \mathrm{~ns}$ \\
Unknown protein (Spot 19) & $0.40^{* *}$ & $0.79 \mathrm{~ns}$ & $0.55 \mathrm{~ns}$ \\
Novel protein (Spot 25) & $\mathbf{3 . 4 2}^{* *}$ & $0.84 \mathrm{~ns}$ & $\mathbf{2 . 7 1}$ \\
\hline
\end{tabular}

independent water-deficit stress showed a good recovery in expression, tending toward normal expression (Table 3).

\section{Discussion}

Physiological, molecular, and metabolic plasticity to an independent heat-stress exposure preceded by a completely different abiotic stress (water deficit) has been documented in tobacco and Arabidopsis (Rizhsky et al. 2002, 2004). Similarly, in our study, rice cultivar N22 showed a higher tolerance (higher spikelet fertility) of heat stress acquired because of a preceding water-deficit stress. Moreover, tolerance to both heat and a combination of heat and water deficit stress is shown to be unique to N22 and a similar response was not documented with entries known for tolerance to either of the stresses (Rang et al. 2011). Although spikelets trapped in the flag-leaf sheath due to reduced peduncle elongation had relatively lower fertility than exserted spikelets, overall weighted average fertility was higher with combined stress over independent heat stress, especially with a longer exposure to high temperature. This is a first report showing acquired tolerance involving two different abiotic stresses during flowering in rice. N22 is highly heat tolerant (Yoshida et al. 1981; Prasad et al. 2006; Jagadish et al. 2008, 2010) and its additional water-deficit tolerance seen in our study and in Selote and Chopra (2004) makes it an ideal candidate for further physiological and molecular approaches to develop multiple abiotic stress-tolerant rice mega-varieties.

Our results follow the conclusion drawn from experiments involving tobacco (Rizhsky et al. 2002) and Arabidopsis (Rizhsky et al. 2004), in which the number of transcripts upregulated during water deficit or heat stress was much higher than during combined stress. The expression patterns of defense-related proteins were significantly higher under combined stress in tobacco than under independent heat or water-deficit stress, i.e., cytosolic heat shock proteins (HSP90, 70, and 100) and small HSPs (cytosolic, mitochondrial, and chloroplastic HSPs; Rizhsky et al. 2002). Similarly, the two small HSPs (16.9 and $17.4 \mathrm{kDa}$ ) identified were more strongly expressed at both the protein and transcript level under combined stress than under independent stresses in rice. Comparing the protein and transcript expression pattern for these two genes, we found differential gene regulation both at the transcriptional and translational phase in response to heat and drought stress. Evidently, HSPs are found to protect plants against various environmental stresses such as heat shock resulting in increasing sHSP expression providing cross-resistance in plants to water deficit (Sun et al. 2001; Cho and Hong 2006), chilling injury (Sebehat et al. 1996; Sato et al. 2001), salt shock (Harrington and Alm 1988), and oxidative injury (Banzet et al. 1998). Sato and Yokoya (2007) showed increased tolerance of rice seedlings of water deficit after prior exposure to heat stress at $42^{\circ} \mathrm{C}$ for $24 \mathrm{~h}$; overexpression of HSPs increased tolerance of water deficit in tobacco (Cho and Hong 2006) and water deficit and salt in Arabidopsis (Sun et al. 2001). The molecular and physiological responses in Arabidopsis (Rizhsky et al. 2004) and tobacco (Rizhsky et al. 2002) were similar to those in rice in many ways when subjected to a combined water-deficit stress and heat stress, suggesting a possible conserved defense mechanism across crops in response to abiotic stresses.

The failure of panicle exsertion under drought stress accounts for spikelet sterility because the unexserted spikelets fail to complete anthesis and shed pollen, even when anther and pistil development is otherwise normal (O'Toole and Namuco 1983; Cruz and O'Toole 1984). One reason for lower fertility in spikelets trapped in the leaf sheath may be a higher tissue temperature due to reduced transpiration, more so with combined water deficit and heat stress rather than a direct effect of water deficit. Liu et al. (2006) exposed susceptible rice genotype IR64 to 50\% flag- 


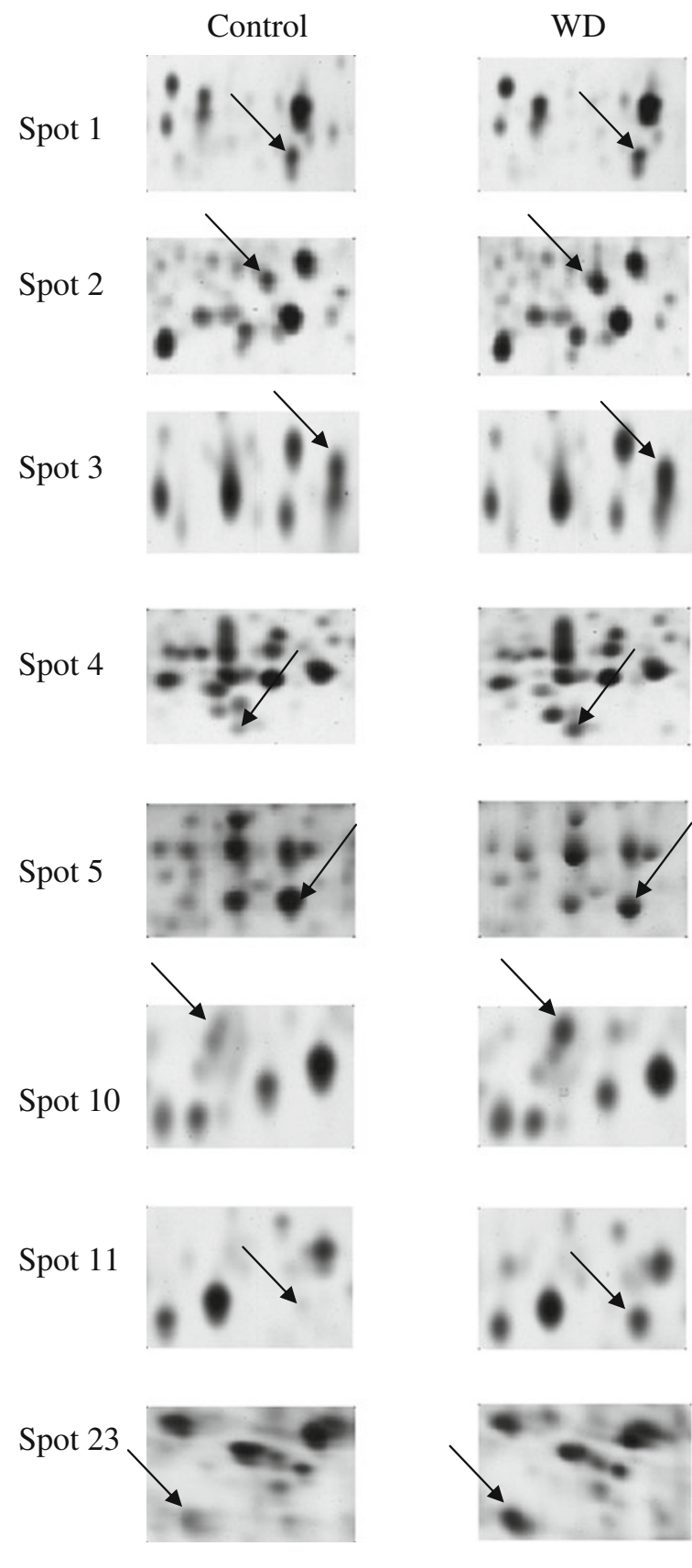

Fig. 3 Proteins up- or down-regulated twofold and significantly varying with water deficit $(W D)$, Heat, and combined water deficit+ heat $(W D+H)$ stress compared with Control (at 5\%) were excised

leaf relative water content (RWC) at flowering and recorded an $80 \%$ decline in fertility compared with a $22 \%$ decline in tolerant Moroberekan even with RWC as low as $40 \%$. N22 is also tolerant of water deficit at flowering with only a $23 \%$ decline in fertility at $50 \%$ to $60 \%$ flag-leaf RWC. However, how much of this tolerance is due to absolute tolerance versus having a higher proportion of spikelets trapped within the leaf sheath with inherently lower fertility remains to be determined.
Heat
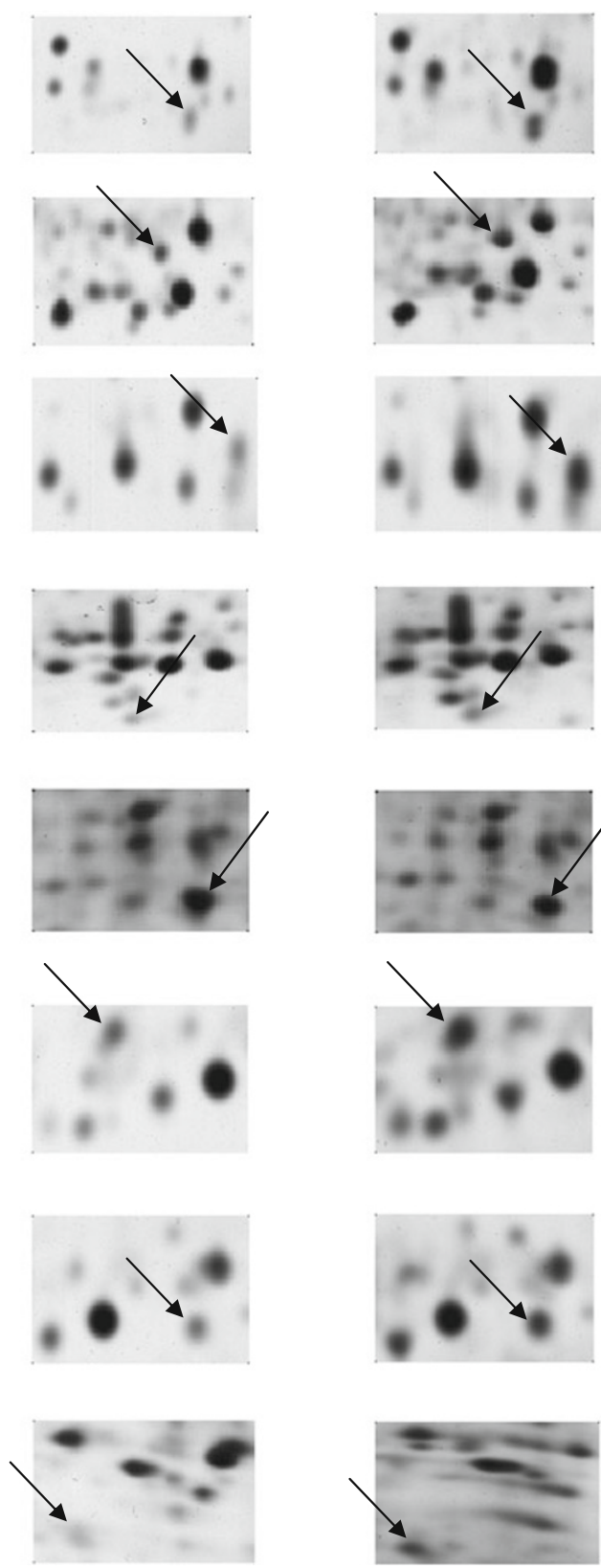

from 2D gels, sequenced using MS MALDI-TOF, and identified by database searches using peptide mass fingerprinting data.

Selote and Chopra (2004) exposed N22 and N118 to water-deficit stress at flowering and found a significant decline in panicle RWC in N118 compared with N22, resulting in a $61 \%$ reduction in yield compared with $29 \%$ in N22. Furthermore, an extremely efficient antioxidant defense system (high activity of superoxide dismutase, enhanced ascorbate and glutathione content) in N22 panicles may play an important role in minimizing waterdeficit stress-induced spikelet sterility (Selote and Chopra 
Control

Spot 7
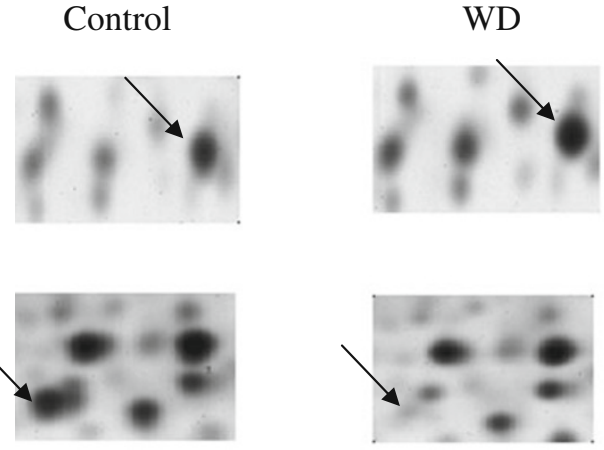

Spot 19
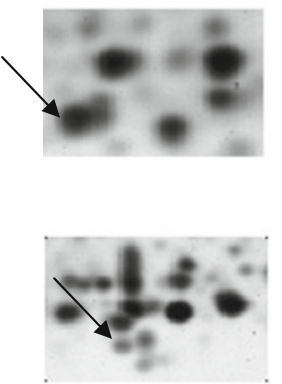

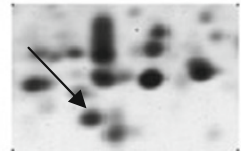

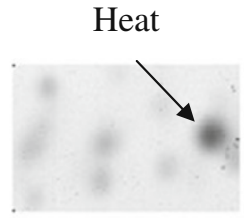
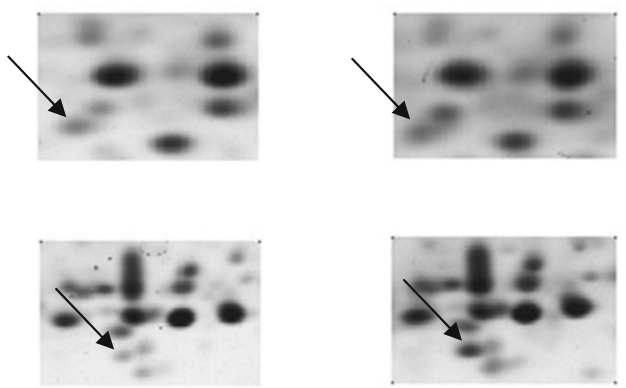

$\mathrm{WD}+\mathrm{H}$
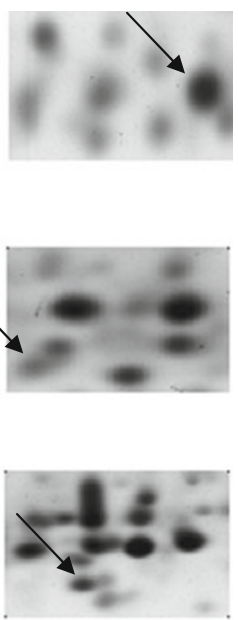

Fig. 4 Proteins up- or down-regulated twofold and significantly varying with water deficit $(W D)$, Heat, and combined water deficit+ heat $(W D+H)$ stress compared with Control (at 5\%) were excised from 2D gels, sequenced using MS MALDI-TOF, but not identified from the available databases using peptide mass fingerprinting data.

pollen could also influence pollen germination either by supplying fructose-6-phosphate for glycolysis or by connecting UDP glucose to support cell wall material biosynthesis for pollen tube growth (Clement and Audran 1995; Karni and Aloni 2002). Using RNAi-mediated suppression, Xu et al. (2008) showed a hexokinase (OsHxK10) to be essentially involved in anther dehiscence and pollen germination.

Apart from the identified annotated proteins from the reference Nipponbare sequence, two significantly upregulated proteins under water deficit and combined stress had no sequence annotation available with the existing database (Table 3). Such unknown genes could be novel and might reveal insights into undisclosed components of stressresponsive pathways and, hence, identifying and validating them should be given high importance (Gollery et al. 2006, 2007; Luhua et al. 2008). One of the un-annotated proteins was also highly down-regulated under water deficit but reverted to normal levels under combined stress and hence behaved similarly to pollen allergens and beta expansin.

All the annotated (eight) and un-annotated (three) proteins are currently being sequenced from the tolerant N22 genotype to further identify functional single nucleotide polymorphisms across tolerant and intolerant accessions for functional validation through transgenic approaches. Such further analysis of the differentially expressed proteins identified using a $2 \mathrm{D}$ approach is essential to consolidate the conclusions drawn from 2D gel expression data, which are complex, requiring cautious interpretation. Furthermore, the best-bet candidate genes will be used to develop gene-specific markers to be incorporated into the existing molecular marker-assisted breeding pipeline for developing multiple abiotic stresstolerant rice mega-varieties.
Fig. 5 Transcript expression patterns for 17.4 and $16.9 \mathrm{kDa}$ HSP in N22 spikelets under Control, water deficit (WD), heat, and combined stress $(W D+H)$ on the first day and after 4 days of stress. GAPDH was used as a positive control. 


\section{Materials and methods}

All the experiments were conducted under controlled environmental conditions at the International Rice Research Institute, Philippines, between 2006 and 2009. Plants were grown under controlled greenhouse conditions and transferred to plant growth chambers to impose heat treatments.

\section{Crop husbandry}

\section{Experiment 1}

Rice (Oryza sativa subsp. indica cv. Nagina [N] 22) seeds were pre-treated at $50^{\circ} \mathrm{C}$ for 3 days to break dormancy. Pre-germinated seeds were sown in trays containing natural clay loam soil mixed with $2.5 \mathrm{~g}$ ammonium sulphate $\left(\mathrm{NH}_{4}\right)_{2} \mathrm{SO}_{4}, 0.5 \mathrm{~g}$ muriate of potash $(\mathrm{KCl})$, and $0.5 \mathrm{~g}$ single superphosphate (SSP). Fifteen-day-old seedlings were transplanted in pots containing $6 \mathrm{~kg}$ of the same clay loam soil mixed with $7.5 \mathrm{~g}\left(\mathrm{NH}_{4}\right)_{2} \mathrm{SO}_{4}, 1.5 \mathrm{~g} \mathrm{KCl}$, and $1.5 \mathrm{~g}$ SSP. An additional $2.5 \mathrm{~g}$ of $\left(\mathrm{NH}_{4}\right)_{2} \mathrm{SO}_{4}$ was added 30 days after transplanting. Three plants per pot were maintained under fully flooded conditions. There were no other major pest or disease problems except the incidence of white fly (Bemissia spp.). Cypermethrin (cymbush) at $0.42 \mathrm{gL}^{-1}$ was sprayed at 15-day intervals, starting 30 days after transplanting, to control white fly infestation.

\section{Experiments 2 and 3}

Seeds were direct sown in 64-well seeding trays and 14day-old seedlings were transplanted into pots containing $6 \mathrm{~kg}$ of clay loam soil. Adequate basal fertilizer [2.0 g $\left(\mathrm{NH}_{4}\right)_{2} \mathrm{SO}_{4}, 1.0 \mathrm{~g} \mathrm{KCl}$, and $1.0 \mathrm{~g} \mathrm{SSP}$ ] was added before transplanting and an additional $2.5 \mathrm{~g}$ of $\left(\mathrm{NH}_{4}\right)_{2} \mathrm{SO}_{4}$ was added 30 days after transplanting. One plant per pot was maintained under fully flooded conditions. Other crop management aspects were similar to experiment 1 . There was no major pest or disease problem.

\section{Greenhouse conditions}

Plants were initially grown under controlled greenhouse conditions with mean air temperature maintained at $29^{\circ} \mathrm{C} /$ $21^{\circ} \mathrm{C}$ day/night (actual; 28.0 $0^{\circ}$ [SD $\{$ standard deviation $\}=$ $\left.0.90] / 19.6^{\circ}[\mathrm{SD}=0.30]\right)$ and relative humidity $(\mathrm{RH})$ at $75 \%$ (actual; 81\% [SD=1.20]) throughout the experimental period. Ambient air temperature and $\mathrm{RH}$ were measured using thermocouples every $10 \mathrm{~s}$ and averaged over $10 \mathrm{~min}$ (Chessell 392, Leesburg, VA, U.S.A.).
Growth chambers

For independent heat and combined stress treatments, plants were transferred to growth chambers (Thermoline, Perth, WA, Australia). The temperature regime was $38^{\circ} \mathrm{C} /$ $21^{\circ} \mathrm{C}$ (day/night) with a gradual increase in temperature from $29^{\circ} \mathrm{C}$ at 0700 hours to $38^{\circ} \mathrm{C}$ at 0830 hour and maintained at this temperature $\left(\mathrm{SD}=0.11^{\circ}\right)$ till 1430 hours $(6 \mathrm{~h})$ with $\mathrm{RH}$ at $75 \%(\mathrm{SD}=1.30)$. Ambient air temperature and RH were measured every $10 \mathrm{~s}$ using thermocouples placed over the canopy and averaged over $10 \mathrm{~min}$ (Chessell 392, Leesburg, VA, U.S.A.). Air circulation inside the chamber was maintained at a speed of $0.5 \mathrm{~m}$ $\mathrm{s}^{-1}$. Photosynthetic photon flux density was maintained at $640 \mu \mathrm{mol} \mathrm{m} \mathrm{m}^{-2} \mathrm{~s}^{-1}$. $\mathrm{CO}_{2}$ concentration was not measured.

\section{Experimental treatments}

All three experiments had a control (no water deficit, $29^{\circ} \mathrm{C}$ day temperature), high day temperature $\left(38^{\circ} \mathrm{C}\right)$, water deficit, and a combined high temperature and water-deficit treatment. Transfers from the controlledtemperature glasshouse $\left(29^{\circ} \mathrm{C}\right.$ day temperature $)$ at anthesis to the growth chambers were used to impose hightemperature treatments. Water-deficit treatments were imposed by withholding water before anthesis so that target levels of stress were achieved at anthesis.

\section{Experiment 1}

Eighteen plants were used for each treatment, namely, control, water deficit, heat stress, and combined stress (Fig. 6a; modified from Rizhsky et al. 2004). The high-temperature treatment was imposed by transferring plants at anthesis to $38^{\circ} \mathrm{C}$ for 1 day. For water-deficit stress, plants with main tillers at three DBH (days before heading) were identified based on the inter-auricle distance (Liu et al. 2006) and tagged. Water-deficit stress was imposed by withholding watering and the water status of the plants was monitored by measuring the RWC of the flag leaves. The following formula was used for measuring RWC (Liu et al. 2006): RWC (\%)= $[(W-\mathrm{DW}) /(\mathrm{TW}-\mathrm{DW})] \times 100$; where, $W=$ initial fresh weight, $\mathrm{DW}=$ dry weight, and TW=turgid weight. Plants for combined water deficit and heat stress were identified with the main tiller at three DBH stage and exposed to water stress as described earlier. Water-deficit-stressed plants were exposed to high temperature from 0830 hours until 1430 hours on the final day of water-deficit stress when the RWC was expected to reach around $40 \%$ to $50 \%$ (Fig. 6a). For proteomic analysis, three biological replicates of spikelets were collected from plants exposed to $29^{\circ} \mathrm{C}$ and $38^{\circ} \mathrm{C}$ day temperatures as control and heat-stressed samples, respectively, in a $50-\mathrm{ml}$ 
falcon tube suspended in liquid N. For water-deficit and combined-stress treatments, spikelets were collected when the flag-leaf RWC was around $40 \%$ to $45 \%$ (Fig 6b). From an independent set of plants exposed to similar stress treatments, spikelets were collected on the first and after four days of stress exposure, for carrying out transcript expression analysis on the most promising genes. All the samples were collected from the top four rachis branches from panicles at heading stage and transferred to $-80^{\circ} \mathrm{C}$ until further use. For both proteomic and transcript expression studies, spikelets collected and used were from only this experiment.

\section{Experiment 2}

Each of the four treatments had five replicate plants. The protocols followed for control and heat stress were similar to experiment 1 , except that the independent heat stress was applied for 5 days during flowering rather

$\mathbf{a}$

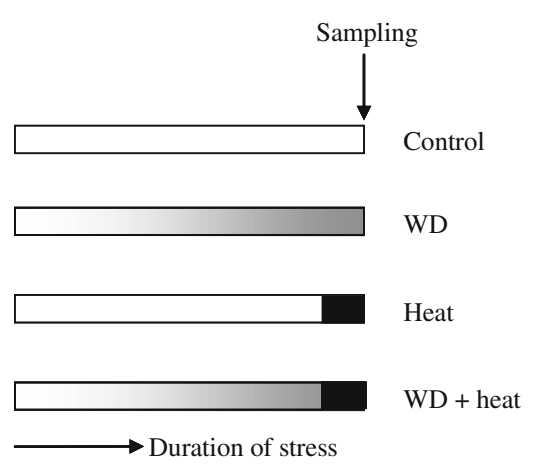

b

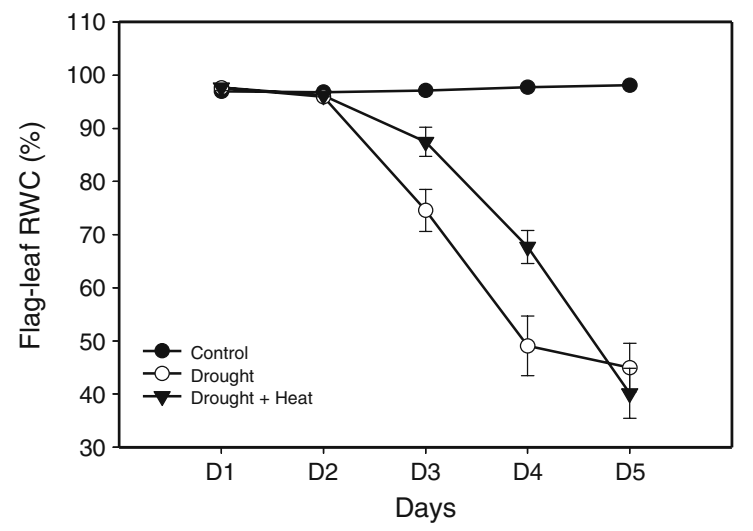

Fig. 6 Schematic presentation of the stress treatments applied before sampling spikelets for protein expression study in experiment 1 (a) and flag-leaf $\%$ relative water content (RWC) used as a measure to determine the intensity of water stress in both water-deficit $(W D)$ and combinedstress treatment (b). In experiment 3 , heat stress and controlled waterdeficit stress were imposed on the starting day of anthesis till the end of than the single day used previously. For water-deficit stress, main tiller monitoring, stage identification, and imposing of water-deficit stress were similar to experiment 1 . Stress was regularly monitored by weighing the pots both in the morning ( 0800 hours) and in the afternoon (1700 hours) till plants reached nearly 50\% to $60 \%$ RWC, morphologically equated to flag-leaf rolling. The evaporated/transpired water, approximately $500 \mathrm{ml}$ per day, was added back to maintain pots at the same water content till the end of the main tiller anthesis, followed by complete flooding. The flag-leaf RWC was not recorded in this experiment. With combined stress, water deficit was imposed as described above with simultaneous exposure to heat stress for $6 \mathrm{~h}$ for 5 days.

\section{Experiment 3}

Seven replicate plants each were used for all four treatments. A similar approach to experiments 1 and 2 was followed for

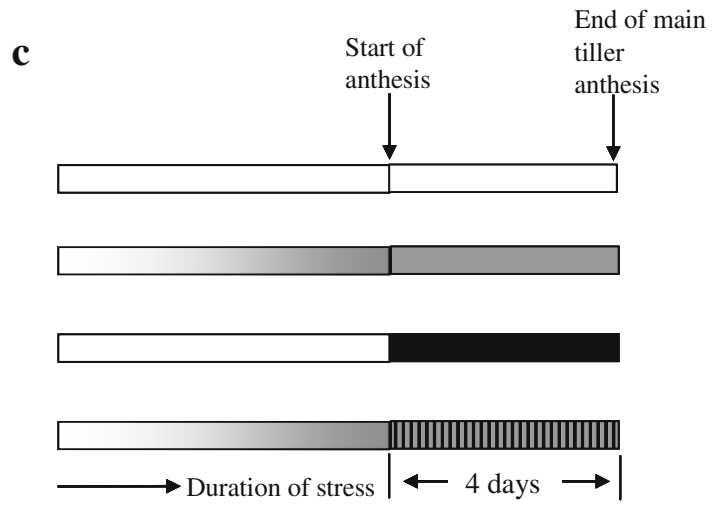

d

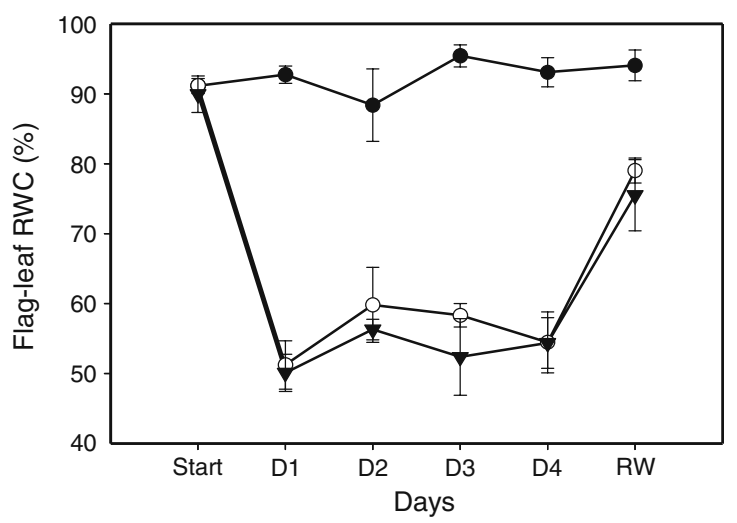

main tiller anthesis (c) and the flag-leaf RWC during the period was continuously monitored for four consecutive flowering days (day 1 $[D 1]$, day $2[D 2]$, day $3[D 3]$, and day $4[D 4])($ d). Duration from the start of stress till the flag-leaf RWC attained the target water content on day $1(D 1)$ was 5 days and the rewatering data were collected 3 days after rewatering (indicated by parallel line breaks in $\mathbf{d}$ ). 
the water-deficit treatment but with more measurements of flag-leaf RWC (Fig. 6c). RWC was measured at the start of the stress treatment, 5 days after the initiation of the stress, which coincided with flag-leaf rolling, on the four following days of flowering and 3 days after rewatering (Fig. 6d) as mentioned in experiment 1 . With the start of the stress treatment coinciding with flag-leaf rolling, pots were regularly weighed (as in experiment 2) and the water used was replenished to maintain the plants in a similar stress conditions till the end of the main-tiller anthesis, followed by complete flooding. For the combined heat and waterdeficit stress, water deficit was imposed as in experiment 2 but plants were exposed to 4 days of high temperature starting from the first day of anthesis for a duration of $6 \mathrm{~h}$, on each of the 4 days.

Protein extraction and 2D-PAGE analysis

Total soluble proteins were extracted from spikelets collected under the above treatments by the trichloro acetic acid precipitation method with minor modifications (Salekdeh et al. 2002). All further processes, including protein concentration determination by Bovine Serum Albumin, protein separation of first-dimensional IEF based on isoelectric point, second-dimensional SDS-PAGE separation based on molecular weights, and staining, were carried out as described by Jagadish et al. (2010).

Image acquisition, data analysis, and protein identification

Silver-stained gels were scanned using a GS-800 densitometer (Bio-Rad) with a resolution of 600 dots and 12 bits per inch. Image visualization, spot detection, and protein quantification were carried out using the Melanie 3 software (GeneBio, Geneva, Switzerland). Twelve-bit images were used for detecting the spots using optimized parameters as follows: number of smooths, 1; Laplacian threshold, 5; partial threshold, 5; saturation, 90; peakness increase, 100; minimum perimeter, 30 . The treatments were compared by calculating the abundance ratio of spots (vol.\% of spot under stress/vol.\% of spot under control; Yan et al. 2005; Jagadish et al. 2010). The vol.\% was determined based on area occupied and the intensity of the protein spot using the above-mentioned parameters. Molecular weight of the protein spot was determined by co-electrophoresis of standard protein markers (Bio-Rad) with the sample to identify internal markers and $p I$ (isoelectric point) was determined by migration of the spots along the $17-\mathrm{cm}$ IPG strip $(4-7 \mathrm{pH})$. Protein spots of interest showing significant quantitative changes during water deficit, heat stress, and combined stress were excised, stained, and identified as explained in Jagadish et al. (2010).

\section{Sampling and observations}

Peduncle elongation and spikelet fertility

Peduncle length was measured from the panicle node to the one immediately below it in all four treatments in both experiments 2 and 3 . Rice panicles do not completely exsert during water-deficit stress. Hence, the number of spikelets within and outside the flag-leaf sheath was counted from all four treatments for both experiments 2 and 3. Seed-set of spikelets inside and outside the leaf sheath was recorded by pressing each of them between the thumb and the forefinger to determine whether the grain was filled or not.

Pollen count and germination on the stigma

Approximately 12 exserted spikelets from outside the leaf sheath were collected at random from the main tillers from all four treatments during experiments 2 and 3. Spikelets were placed in vials containing FAA (50\% absolute ethanol, 5\% acetic acid, and $27 \%$ formaldehyde) fixative. Stigmas were dissected out and in vivo pollen count and pollen germination were recorded using aniline blue stain according to Jagadish et al. (2010). Pollen grains with tubes longer than their diameter were considered as germinated (Luza et al. 1987).

\section{Statistical analysis}

Protein abundance (vol.\%) values across treatments and replications obtained from Melanie 3 software were analyzed as a completely randomized design using Genstat 8.1 (Rothamsted Experimental Station). Three replicates from water deficit, heat, and combined stress were used to check for significant changes in expression compared with the control. All physiological parameters, including peduncle length, pollen count, pollen germination, and spikelet fertility, were analyzed as a completely randomized design using Genstat ver. 11. The weighted average fertility was used to calculate the average fertility of spikelets in each panicle using the following formula: (Percent fertility of spikelets within the sheath $\times$ Percent number of spikelets trapped inside the sheath $)+($ Percent fertility of spikelets outside the sheath $\times$ Percent number of spikelets exserted).

Acknowledgments We thank the Felix Scholarship for funding the PhD of SVK Jagadish. The University of Reading and the International Rice Research Institute are thanked for providing facilities to support this research. USAID-BMGF (CSISA) are thanked for supporting the ongoing work on validation of these candidate genes. This research has been facilitated by access to the Australian Proteome Analysis Facility established under the Australian Government's Major National Research Facilities Program. Bill Hardy from IRRI is thanked for editing the manuscript. The experiments comply with the current laws of Philippines. 


\section{References}

Abbott A. A post-genomic challenge: learning to read patterns of protein. Nature. 1999;402:715.

Banzet N, Richaud C, Deveaux Y, Kazmaier M, Gagnon J, Triantaphylides C. Accumulation of small heat shock proteins, including mitochondrial HSP22, induced by oxidative stress and adaptive response in tomato cells. Plant J. 1998;13:519-27.

Cho EK, Hong CB. Over-expression of tobacco NtHSP70-1 contributes to drought stress tolerance in plants. Plant Cell Rep. 2006;25:349-58.

Cosgrove DJ, Bedinger P, Durachko DM. Group I allergens of grass pollen as cell wall-loosening agents. Proc Natl Acad Sci USA. 1997;94:6559-64.

Clement C, Audran JC. Anther wall layers control pollen sugar nutrition in Lilium. Protoplasma. 1995;187:172-81.

Cline WR. Global warming and agriculture: impact estimates by country. Washington, D.C: Center for global development and Peterson Institute for International Economics; 2007.

Cruz RT, O'Toole JC. Dryland rice response to an irrigation gradient at flowering stage. Agron J. 1984;76:178-83.

Dai S, Li L, Chen T, Chong K, Xue Y, Wang T. Proteomic analyses of Oryza sativa mature pollen reveal novel proteins associated with pollen germination and tube growth. Proteomics. 2006;6:2504-29.

Easterling WE, Aggarwal PK, Batima P, Brander KM, Erda L, Howden $\mathrm{SM}$, et al. Food, fiber and forest products. In: Parry ML, Canziani OF, Palutikof JP, van der Linden PJ, Hanson CE, editors. Climate change 2007: Impacts, adaptation and vulnerability. Contribution of working group II to the fourth assessment report of the IPCC. Cambridge: Cambridge University Press; 2007. p. 273-313.

Gollery M, Harper J, Cushman J, Mittler T, Girke T, Zhu JK, et al. What makes species unique? The contribution of proteins with obscure features. Genome Biol. 2006;7:757.

Gollery M, Harper J, Cushman J, Mittler T, Mittler R. POFs: what we don't know can hurt us. Trends Plant Sci. 2007;12:492-6.

Harrington HM, Alm DM. Interaction of heat and salt shock in cultured tobacco cells. Plant Physiol. 1988;88:618-25.

Hayashi T, Yamaguchi T, Nakayama K, Komatsu S, Koike S. Susceptibility to coolness at the young microspore stage under high nitrogen supply in rice (Oryza sativa L.): proteome analysis of mature anthers. Plant Prod Sci. 2006;9:212-8.

Imin N, Kerim T, Rolfe BG, Weinman JJ. Effect of early cold stress on the maturation of rice anthers. Proteomics. 2004;4:1873-82.

Imin N, Kerim T, Weinman JJ, Rolfe BG. Characterisation of rice anther proteins expressed at the young microspore stage. Proteomics. 2001;1:1149-61.

IPCC (2007) Summary for policy makers. In: Climate Change 2007, The Physical Science Basis. 9

Jagadish SVK, Craufurd PQ, Wheeler TR. High temperature stress and spikelet fertility in rice (Oryza sativa L.). J Exp Bot. 2007;58:1627-35.

Jagadish SVK, Craufurd PQ, Wheeler TR. Phenotyping parents of mapping populations of rice (Oryza sativa $\mathrm{L}$.) for heat tolerance during anthesis. Crop Sci. 2008;48:1140-6.

Jagadish SVK, Muthurajan R, Oane R, Wheeler TR, Heuer S, Bennett $\mathrm{J}$, et al. Physiological and proteomic approaches to dissect reproductive stage heat tolerance in rice (Oryza sativa L.). J Exp Bot. 2010;61:143-56.

Karni L, Aloni B. Fructokinase and hexokinase from pollen grains of bell pepper (Capsicum annuиm L.): possible role in pollen germination under conditions of high temperature and $\mathrm{CO}_{2}$ enrichment. Ann Bot. 2002;90:607-12.

Kerim T, Imin N, Weinman JJ, Rolfe BG. Proteome analysis of male gametophyte development in rice anthers. Proteomics. 2003;3:738-51.
Komatsu S. Rice proteome database: a step towards functional analysis of the rice genome. Plant Mol Biol. 2005;59:179-90.

Liu JX, Liao DQ, Oane R, Estenor L, Yang XE, Li ZC, et al. Genetic variation in the sensitivity of anther dehiscence to drought stress in rice. Field Crops Res. 2006;97:87-100.

Luhua S, Ciftci-Yilmaz S, Harper J, Cushman J, Mittler R. Enhanced tolerance to oxidative stress in transgenic Arabidopsis plants expressing proteins of unknown function. Plant Physiol. 2008; 148:280-92.

Luza JG, Polito VS, Weinbaum SA. Staminate bloom date and temperature responses to pollen germination and tube growth in two walnut (Juglans) species. Am J Bot. 1987;74:1898-903.

Matsui T, Omasa K, Horie T. High temperature at flowering inhibits swelling of pollen grains, a driving force for anther dehiscence in rice (Oryza sativa L.). Plant Prod Sci. 2000;3:430-4.

Mittler R. Abiotic stress, the field environment and stress combination. Trends Plant Sci. 2006;11:15-9.

O'Toole JC, Namuco OS. Role of panicle exsertion in water-stress induced sterility. Crop Sci. 1983;23:1093-7.

Pandey A, Mann M. Proteomics to study genes and genomes. Nature. 2000;405:837-46.

Prasad PVV, Boote KJ, Allen LH, Sheehy JE, Thomas JMG. Species, ecotype and cultivar differences in spikelet fertility and harvest index of rice in response to high temperature stress. Field Crops Res. 2006;95:398-411.

Rang ZW, Jagadish SVK, Zhou QM, Craufurd PQ, Heuer H. Effect of high temperature and water stress on pollen germination and spikelet fertility in rice. Environ Exp Bot. 2011;70:58-65.

Rizhsky L, Liang H, Shuman J, Shulaev V, Davletova S, Mittler R. When defense pathways collide: the response of Arabidopsis to a combination of drought and heat stress. Plant Physiol. 2004;134:1683-96.

Rizhsky L, Hongjian L, Mittler R. The combined effect of drought stress and heat shock on gene expression in tobacco. Plant Physiol. 2002;130:1143-51.

Salekdeh GhH, Siopongco J, Ghareyazie B, Bennett J. Proteomic analysis of rice leaves during drought stress and recovery. Proteomics. 2002;2:1131-45.

Sato Y, Yokoya S. Enhanced tolerance to drought stress in transgenic rice plants overexpressing a small heat-shock protein, sHSP17.7. Plant Cell Rep. 2007;27:329-34.

Sato Y, Murakami T, Funatsuki H, Matsuba S, Saruyama H, Tanida M. Heat shock-mediated APX gene expression and protection against chilling injury in rice seedlings. J Exp Bot. 2001;52:145-51.

Sebehat A, Weiss D, Lurie S. The correlation between heat shock protein accumulation and persistence and chilling tolerance in tomato fruits. Plant Physiol. 1996;110:531-7.

Selote DS, Chopra RK. Drought induced spikelet sterility is associated with an inefficient antioxidant defense in rice panicles. Physiol Plant. 2004;121:462-71.

Sun W, Bernard C, Cotte BV, Montagu MV, Verbruggen N. At-HSP17.6A, encoding a small heat-shock protein in Arabidopsis, can enhance osmotolerance upon overexpression. Plant J. 2001;27:407-15.

Wassmann R, Jagadish SVK, Sumfleth K, Pathak H, Howell G, Ismail A, et al. Regional vulnerability of climate change impacts on Asian rice production and scope for adaptation. Adv Agron. 2009;102:99-133.

Xu FQ, Li XR, Ruan YL. RNAi-mediated suppression of hexokinase gene OsHXK10 in rice leads to non-dehiscent anther and reduction of pollen germination. Plant Sci. 2008;175:674-84.

Yan S, Tang Z, Su W, Sun W. Proteomic analysis of salt stressresponsive proteins in rice root. Proteomics. 2005;5:235-44.

Yoshida S, Satake T. Mackill DS. High temperature stress in rice. IRRI Res Pap Ser. 1981;67.

Zivy MA, de Vienne D. Proteomics: a link between genomics, genetics and physiology. Plant Mol Biol. 2000;44:575-80. 